Maria Maeno ${ }^{1}$

Rodolfo Andrade de Gouveia Vilela ${ }^{2}$

\title{
Reabilitação profissional no Brasil: elementos para a construção de uma política pública
}

\author{
Occupational rehabilitation in Brazil - elements for the \\ development of public policy
}

\author{
${ }^{1}$ Mestre em Saúde Pública, pesqui- \\ sadora da Fundação Jorge Duprat \\ Figueiredo de Segurança e Medicina do \\ Trabalho (Fundacentro), Ministério do \\ Trabalho e Emprego. \\ ${ }^{2}$ Professor Doutor da Faculdade de \\ Saúde Pública da Universidade de São \\ Paulo. \\ Contato: \\ Maria Maeno \\ Rua Capote Valente, 710 - Pinheiros, \\ São Paulo/ SP \\ CEP: 05409-002 \\ E-mail: \\ maria.maeno@fundacentro.gov.br
}

Recebido: 06/07/2009

Revisado: 04/03/2010

Aprovado: 09/03/2010

\section{Resumo}

Partindo de uma retrospectiva histórica da reabilitação profissional, o objetivo do presente ensaio é refletir sobre as possibilidades de se construir uma política pública, tendo como objetivo a real reinclusão social dos acidentados e adoecidos e não um mecanismo de desfecho burocrático para a redução de custos com benefícios previdenciários. Voltado para os trabalhadores com restrições decorrentes de acidentes traumáticos, o serviço de reabilitação profissional do Instituto Nacional de Seguro Social (INSS), existente até os anos 1990, mostrava-se insuficiente para promover a reinserção de trabalhadores com agravos de perfil epidêmico, particularmente Lesões por Esforços Repetitivos/Distúrbios Osteomusculares Relacionados ao Trabalho (LER/DORT). Nessa época, reflexo da política privatizante, promoveu-se um desmonte nessas estruturas dentro do INSS e a delegação da reinserção dos trabalhadores às empresas. A construção de uma política pública de reabilitação profissional exige: a inserção da saúde do trabalhador nas políticas de desenvolvimento econômico; a desconstrução da cultura e da máquina previdenciária voltada prioritariamente para os custos; a real articulação da Saúde e da Previdência Social em projetos nacionais e locais; a inclusão do caráter distributivo nos planos de modernização; o monitoramento da trajetória dos trabalhadores; e a transparência institucional.

Palavras-chave: reabilitação profissional; reinserção no mercado de trabalho; política pública; incapacidade; privatização da previdência social.

\begin{abstract}
Starting from a historical review of occupational rehabilitation, this essay reflects on the possibilities of structuring a public policy towards a real social reinclusin of the injured and diseased workers, and not as a bureaucratic mechanism to reduce social security benefit costs. Aimed at workers with disabilities caused by traumatic accidents, the occupational rehabilitation department of the National Social Security Institute (INSS) in Brazil, which existed until the 1990s, proved to be inadequate to reintegrate workers with health problems of epidemic profile, particularly Repetitive Strain Injuries/Work-Related Musculoskeletal Disorders (RSI/WRMD). At that time, as a consequence of a privatizing policy, these structures within INSS were dismantled and companies had to assume the reintroduction of workers. The development of an occupational rehabilitation policy requires the inclusion of occupational health as a topic in economic development policies, the deconstruction of the current thought and system geared primarily by pension costs, the real articulation of Health and Social Welfare in national and local projects, the inclusion of a distributive quality in the modernization plans, the monitoring of workers' trajectory, and institutional transparency.
\end{abstract}

Keywords: occupationl rehabilitation; reintroduction in the labor market; public policy; disability; institutional transparency; social security privatization. 


\section{O trabalho e a incapacidade, aspectos conceituais}

A sociedade e as suas instituições conservam, de modo geral, a visão taylorista de que o trabalho é algo estável, que pode ser fracionado em etapas simples de fácil execução, cujo sucesso depende de um controle e de um gerenciamento racionais. O trabalho seria, então, uma entidade abstrata, única e homogênea, admitindo poucas variações e categorizações. Por outro lado, o ser humano em situação de trabalho é visto como uma variável também padronizável, desde que haja uma "seleção científica” dos mais aptos. A ideia do operário padrão parte do pressuposto de um ser humano estável, que mantém ao longo do tempo suas aptidões pessoais "normais", capacitadas para qualquer atividade de trabalho.

O mundo real, no entanto, é bem distinto destas idealizações: o trabalho e o ser humano são marcados pela variabilidade, pela complexidade e pela subjetividade como bem ensina a ergonomia da corrente francesa (WISNER, 1994). Qual seria o perfil ideal de trabalhador para a atividade de coletor de lixo, que, aboletado nos caminhões, desce correndo para pegar quilos de inúmeros sacos de lixo e os arremessa para os trituradores, por horas a fio? Ou para a atividade de corte manual de cana sob altas temperaturas climáticas, com metas a cumprir, alto gasto energético e sobrecarga física? Dificilmente um homem com mais de 50 anos de idade, mesmo que hígido, poderia exercer qualquer uma das atividades citadas por limitações impostas pela idade. Tampouco um jovem de 24 anos, com hérnia de disco, teria condições para ocupar esses postos. Paralelamente a certa visibilidade social de aspectos da penosidade de atividades de trabalho como essas, há uma aceitação das imagens de trabalhadores sujos, com risco de morte a cada dia, como se o perigo e as condições de trabalho inadequadas fossem inerentes a determinados processos laborais. Adicionalmente, outros aspectos do trabalho vêm sendo estudados sobressaindo-se pela sua penosidade menos visível. Jinkings (2006) chama a atenção para formas sistêmicas de organização do trabalho em um contexto de programas de qualidade total e práticas gerenciais que buscam uma suposta identidade cada vez maior dos trabalhadores com as estratégias das empresas e sua adesão física e psíquica. Entre outros, é o caso de bancários (JINKINGS, 2006) e trabalhadores das centrais de teleatendimento, chamadas por Oliveira (2009) de central de teleatividades, setor também estudado por Venco (2006) nos seus aspectos organizacionais e nas repercussões sobre a saúde dos que nele trabalham. Padecem da corrida atrás do cumprimento de metas, das pressões para atingi-las, do medo de exclusão diante dos fracassos e de critérios que extrapolam a qualificação profissional, adoecendo física e mentalmente.

A abordagem adequada desse mundo complexo do trabalho e de seus efeitos sobre a saúde requer referências conceituais abrangentes de vigilância e promoção da saúde, que considerem a inter-relação entre estas dimensões, o caráter social e a participação da sociedade como fundamentais para o sucesso das intervenções (BRASIL, 1998; MACHADO, 1996; PINHEIRO, 1996; MACHADO, 2005).

A reabilitação profissional vista sob este ângulo é entendida como parte do processo de intervenção que incide sobre o indivíduo, de modo articulado com a intervenção sobre o processo terapêutico e sobre as condições nocivas de trabalho, que geraram o agravo e/ou acolherão novamente o trabalhador. Portanto, ela deixa de ser vista como uma ilha isolada. Compreende-se, assim, que a atuação em qualquer nível do processo de produção de acidentes e doenças relacionados ao trabalho ou no agravamento de suas consequências clínicas, familiares e sociais tem, direta ou indiretamente, sempre um caráter preventivo.

O objetivo deste ensaio é a produção de uma reflexão sobre as possibilidades e as condições para que a reabilitação profissional no Brasil venha a ser um processo de real reinclusão social dos acidentados e adoecidos, deixando de ser apenas um mecanismo cujos entendimentos e práticas visem ao desfecho administrativo dos casos em gozo de benefícios previdenciários.

\section{Reabilitação profissional no Brasil: contexto histórico}

A reabilitação da capacidade funcional do trabalhador, presente na legislação previdenciária (BRASIL, 1944), inicialmente era citada como "readaptação profissional" e "reaproveitamento do empregado acidentado" e tinha como objeto restituir, parcial ou totalmente, a todo incapacitado para o trabalho, a "capacidade na primitiva profissão ou em outra compatível com as suas novas condições físicas”. A forma prevista para atingir esse objetivo restringia-se à "prática da fisioterapia, da cirurgia ortopédica e reparadora” e ao "ensino convenente em escolas profissionais especiais", o que refletia a natureza das restrições físicas, fundamentalmente decorrentes de acidentes do trabalho traumáticos, e a abordagem terapêutica vigente à época. Eram práticas executadas pelas Caixas de Aposentadorias e Pensões (CAPs) e pelos Institutos de Aposentadorias e Pensões (IAPs). Com a estatização do Seguro de Acidente do Trabalho (SAT) no Instituto Nacional de Previdência Social (INPS), em 1967, a legislação adotou a expressão reabilitação profissional, vinculada a programas de prevenção de acidentes do trabalho da previdência social, sem, no entanto, explicitar o seu significado e, tampouco, quaisquer procedimentos. Passou-se a garantir fonte de custeio a cargo exclusivamente da empresa (BRASIL, 1967).

Em 1976, a legislação tornou a reabilitação profissional obrigatória ao acidentado do trabalho (BRASIL, 1976a). No seu regulamento, a reabilitação profissional ficou caracterizada como um direito do acidentado do 
trabalho e foi contemplada em uma seção, ainda que sucinta. Nesta, é citado um programa de reabilitação profissional que se destina, quando indicado e necessário, ao "acidentado que, em consequência do acidente, se torna incapaz para o exercício da sua atividade" (BRASIL, 1976b).

Na legislação atual ampliou-se o direito à reabilitação profissional ao dependente, além do segurado, acidentado do trabalho ou não, e se determinou que o segurado, em gozo de auxílio-doença (benefício temporário por incapacidade), impossibilitado de recuperação para sua atividade habitual, "deverá submeter-se ao processo de reabilitação profissional para o exercício de outra atividade”. Neste caso, não pode ter o benefício temporário suspenso "até que seja dado como habilitado para o desempenho de nova atividade, que lhe garanta a subsistência ou, quando considerado não recuperável, for aposentado por invalidez" (BRASIL, 1991). O regulamento da lei previdenciária cita alguns procedimentos, incluindo a avaliação do potencial laborativo, a orientação e o acompanhamento da programação profissional, a articulação com a comunidade com vistas ao reingresso no mercado do trabalho e o acompanhamento e a pesquisa da fixação no mercado de trabalho, preferencialmente por uma equipe multiprofissional. Isenta a Previdência Social da manutenção do segurado no mesmo emprego ou da sua colocação em outro para o qual for reabilitado, deixando claro que o processo de reabilitação profissional cessa com a emissão de um certificado que indique a função para a qual o reabilitando foi capacitado profissionalmente (BRASIL, 1999). Isto é, explicita-se o resultado esperado, parcial e incompleto, que é a habilitação e a possibilidade de reinserção, e não a reinserção efetiva.

A vinculação da reabilitação profissional ao órgão segurador, a fragmentação das atuações dos órgãos de Estado e as escolhas governamentais no desenvolvimento do processo político do país levaram à implementação de um serviço sem a necessária articulação com os órgãos assistenciais, nem com os órgãos fiscalizadores das condições de trabalho e, tampouco, com o corpo pericial da própria Previdência Social (TAKAHASHI, 2006). Estruturada em unidades localizadas nas capitais brasileiras e em algumas grandes cidades do interior, denominadas Centros e Núcleos de Reabilitação Profissional (CRP e NRP) do Instituto Nacional de Previdência Social (INPS) e depois Instituto Nacional de Seguro Social (INSS) sua atuação sempre foi tímida dentro dos limites de procedimentos administrativos que, ao mesmo tempo em que propiciavam intervenções para reduzir as desvantagens decorrentes das incapacidades, tornavam-na parte do mecanismo regulador das finanças previdenciárias, sem qualquer intervenção sobre as condições de trabalho. Em seu estudo sobre a reabilitação profissional do INSS, Matsuo (1997) destaca que os técnicos entrevistados eram profissionais experientes e empenhados em fazer um bom trabalho, mas não havia uma definição do que consistia a reabilitação. Segundo os entrevistados, "o CRP não tem que se meter na empresa. O nosso papel é reabilitar o acidentado. Preparar o trabalhador para retornar ao trabalho". As entrevistas também mostraram que outros questionavam o real papel do CRP, considerando que tanto o encaminhamento do segurado à reabilitação profissional, como a avaliação da aptidão do segurado para o trabalho e a concessão de benefícios eram competência da perícia médica e que o INSS não influenciava efetivamente na recolocação do trabalhador, o que era feito pela empresa.

Sob essa característica de pouca consistência conceitual, com uma clientela predominante de acidentados com sequelas físicas visíveis, a recolocação era feita sem que isso significasse uma real reintegração do acidentado à vida social e profissional.

Na década de 1990, com o aumento de segurados com restrições decorrentes de doenças ocupacionais, particularmente Lesões por Esforços Repetitivos ou Distúrbios Osteomusculares Relacionados ao Trabalho (LER/DORT), os procedimentos adotados pelos CRP e pelos NRP evidenciaram a sua insuficiência mesmo para o papel que desempenhavam. Sua clientela, até então predominante de trabalhadores com sequelas de acidentes do trabalho, passou a coexistir com outros, que apresentavam restrições físicas pouco visíveis, decorrentes de doenças de evolução crônica e de forte sofrimento psíquico. Esses casos comumente eram oriundos de empresas com histórico de grande número de acometidos e que, apesar disso, mantinham o ambiente de trabalho inalterado, não adotando medidas preventivas. As estatísticas da Previdência Social mostram que, entre 1988 e 1991, menos de $1 \%$ do total de agravos ocupacionais registrados era de doenças, entre 1992 e 1995, o percentual aumentou até $5 \%$, com picos de 8,8\% e 8,6\%, respectivamente nos anos de 1996 e 1997, para se manterem nos anos subsequentes entre 5,5\% a 7,5\%. Apesar das oscilações, percebia-se uma tendência de aumento do peso das doenças, com grande predomínio das LER/ DORT (BRASIL, 1997). Impulsionadas por essa mudança no perfil da origem das restrições dos trabalhadores encaminhados à reabilitação profissional, algumas experiências isoladas se desenvolveram, fruto do esforço de profissionais articulados com o movimento social e com os órgãos do Sistema Único de Saúde (SUS). Eram experiências que tinham diretrizes mais amplas, tanto no tocante aos conceitos de saúde, de incapacidade e de reabilitação profissional, como na forma intersetorial, sincronizadas às necessidades reais dos trabalhadores.

Ao mesmo tempo, já ocorria um sucateamento da capacidade instalada e dos recursos humanos nos CRP e nos NRP em decorrência de um processo de minimização do papel do Estado, iniciado no final da década de 1980 e intensificado na década de 1990, e de uma compreensão de que a reabilitação profissional era mais um benefício da Previdência Social e não um cuidado à saúde (TAKAHASHI; IGUTI, 2008). Apesar de tentativas de resistência a esse desmonte, durante a década de 1990, testemunhou-se a extinção da reabilitação profissional do INSS, já descrita detalhadamente por Bernardo (2006) e Takahashi (2006). 
Para fins didáticos, será utilizada, neste artigo, a divisão em três fases do processo de mudanças ocorridas na reabilitação profissional do INSS, após a Constituição Federal de 1988, utilizada por Takahashi (2006).

Na primeira fase, concomitantemente à emergência de movimentos sociais e à implementação do SUS, entre 1993 a 1994, pautaram-se questionamentos aos modelos estruturais centralizados e aos conceitos que consideravam a incapacidade diretamente relacionada à doença ou ao trauma, que exigia essencialmente a assistência médica individual. Esses questionamentos tiveram expressão no surgimento de experiências locais e regionais, de natureza interdisciplinar e interinstitucional (TAKAHASHI, 2006).

A segunda fase, de 1995 a 2000, simbolizada pelo Plano de Modernização da Reabilitação Profissional do INSS, consolidou a hegemonia do modelo reducionista da atenção, de delegação da administração da reinserção ao trabalho nas empresas, e o desmonte dos CRP e dos NRP, já em fase de decadência, conforme mencionado (TAKAHASHI, 2006). Eram reflexos do processo de privatização em curso da Previdência Social, consonante com o que havia ocorrido em vários países da América Latina (COELHO, 2003).

Embora a privatização da Previdência Social de fato não tenha ocorrido no Brasil, ao longo dessas últimas décadas observam-se inúmeros procedimentos que, em suas ordens internas, expressam interpretações da legislação com foco na contenção de custos e em formas de gestão que se assemelham às empregadas em seguradoras privadas. Mendes (2006) detalha as formas das práticas que se distanciavam da legislação por meio de normas internas, "acordos" e exigências implícitas por ocasião de seu estudo. Cita, entre as exigências implícitas:

Não estabelecimento de nexo, não concessão de benefícios, não informação dos direitos do segurado, a negativa da CAT (se não emitida pelo médico da empresa), vinculando-as à avaliação de qualidade e do desempenho da atividade pericial. (p. 113)

Caetano (2006), partindo do pressuposto de que o Regime Geral de Previdência Social (RGPS) é deficitário, discute o "potencial das reformas em práticas administrativas na contenção, ainda que parcial, do déficit do RGPS”. Advoga que o "ponto positivo dessas reformas é seu trâmite político muito mais simples que as reformas constitucionais necessárias a um ajuste mais profundo", fortalecendo uma forte cultura institucional de defesa corporativa, baseada em enxugamento de gastos, sobrepondo-se ao senso de justiça e de seguridade social. São emblemáticos alguns estudos apresentados por peritos médicos do INSS, em seu segundo congresso nacional, que expressam supostamente a grande preocupação com a gestão, entendida como enquadramento de resultados de suas atividades nas normas e metas estipuladas por ordens internas do órgão segurador, sem a preocupação com um enfoque mais amplo e de questionamento sobre o mérito da questão em tela. Morais (2009), por exemplo, realizou um estudo visando avaliar o impacto da assistência técnica pelos peritos do INSS nos processos judiciais contra o órgão, concluindo que essa atuação "determinou o curso favorável das ações judiciais para o INSS, trazendo um ganho econômico significativo para a instituição", o qual "trata-se da última linha de defesa do INSS”. Nenhuma palavra sobre o mérito dos processos. Outro perito (TEIXEIRA JUNIOR, 2009), ao analisar "as conclusões obtidas a partir das avaliações do potencial laborativo e o perfil dos desligamentos de programas de reabilitação profissional realizados nos anos de 2007 e 2008, na Unidade Técnica de Reabilitação do Recife”, concluiu que:

\begin{abstract}
Os dados do programa de reabilitação profissional mostram que, somando-se os percentuais de retorno à função diversa, retorno para a mesma atividade e retorno para uma atividade diversa tem-se um percentual de $74 \%$. Ou seja, concluiu-se que houve desempenho do programa de reabilitação profissional, com reinserção no mercado de trabalho, resultado compatível com o preconizado pela OI DIRBEN nº 116/2005.
\end{abstract}

Mais uma vez, mostra-se presente a preocupação em enquadrar-se a um sistema de gestão que prevê um determinado número de segurados com programas de reabilitação profissional concluídos, sem qualquer consideração sobre a qualidade desses programas e sobre as necessidades dos trabalhadores.

Essa preocupação contábil e administrativa é sentida em outras avaliações do desempenho da Previdência Social. Siano (2009) analisou as influências da implementação da cobertura previdenciária estimada pela Copes $^{3}$ sobre os benefícios por incapacidade concedidos a segurados com transtornos psíquicos, em dois períodos, concluindo que:

O perfil de concessão de benefícios por incapacidade a segurados com diagnóstico de transtornos mentais sofreu alterações durante os períodos de mudanças na legislação previdenciária, com redução dos deferimentos pela Perícia Médica, do número de renovações do benefício e do tempo de afastamento concedido.

Não se deteve em qualquer questionamento ou análise sobre a adequação desses procedimentos do ponto de vista do segurado e da sua saúde e sobre o cumprimento dos objetivos da previdência social no tocante à cobertura prevista em lei. Ressalte-se que a Copes, de agosto de 2005 a agosto de 2006, foi instituída por meio de ordens internas, cujo acesso era restrito apenas aos servidores do INSS. Em 2006 foi objeto de uma portaria (BRASIL, 2006a) e de um decreto (BRASIL, 2006b). Emblemático da polêmica sobre essa questão, cita-se o exemplo de negação de provimento pelo juízo federal a um recurso do INSS contra uma tutela antecipada, que

\footnotetext{
${ }^{3}$ Copes: instituída em agosto de 2005, é um mecanismo pericial que define uma data de cessação de benefício no momento em que este é concedido, obrigando o segurado a pedir prorrogação caso não se sinta recuperado na data estimada para o retorno ao trabalho.
} 
havia determinado o restabelecimento do benefício cessado, de forma programada, a uma segurada (BRASIL, 2009a). Baseado na lei previdenciária que determina ao segurado a concessão do auxílio-doença a contar do $16^{\circ}$ dia do afastamento da atividade ou a contar da data do início da incapacidade e "enquanto ele permanecer incapaz” (BRASIL, 1991), entendeu o Juiz Relator que os atestados médicos apresentados pela reclamante lhe conferiam a incapacidade para exercer suas "funções laborativas" habituais, não sendo necessária a existência da "incapacidade absoluta e irrecuperável". Continuou, ainda, fundamentado no artigo 62 da lei previdenciária, que o segurado em gozo de "auxílio-doença e insusceptível de recuperação para sua atividade habitual deveria submeter-se ao processo de reabilitação profissional para o exercício de outra atividade”. E que o benefício não poderia ter sido cessado até que houvesse habilitação "para o desempenho de nova atividade que lhe garanta a subsistência ou, quando considerado não recuperável, for aposentado por invalidez" (BRASIL, 1991).

Pergunta simples postada por um segurado, mas não respondida, expressa a sensação de impotência diante de tantos dissensos:

Estava em benefício desde 07/2001 e recebi alta em 30/06/2009, mesmo estando doente. Como já tinha solicitado um $\mathrm{PR}^{4}$ para este benefício em 2007, só me deram a opção de entrar com recurso. O médico do banco me considerou inapto para o retorno ao trabalho, e me informou que eu deveria entrar com o recurso e aguardar, em casa, o resultado, e que infelizmente eu ficaria sem receber salário até quando o recurso for julgado. O problema é que o recurso demora, e o INSS pode negar. O que devo fazer para não ficar sem salário? $\mathrm{O}$ meu benefício e espécie B91. ${ }^{5}$

A terceira fase de mudanças na Reabilitação Profissional foi a da implementação do Projeto Reabilita, iniciada em 2001 e ainda vigente nos dias atuais, fundamentada no regulamento da Previdência Social (TAKAHASHI, 2006). Sua característica principal tem sido um processo de recolocação sob a responsabilidade institucional de orientadores profissionais e não mais de equipes de reabilitação profissional. Conforme artigos da atual chefe da Divisão de Reabilitação Profissional do INSS, entre as ações não implementadas do Projeto está a "não recomposição da equipe de atendimento” (CANALONGA, 2009a, 2009b).

Muitos desses orientadores profissionais não têm familiaridade com o mundo do trabalho real e com as suas exigências. Seus procedimentos restringem-se à homolo- gação de um processo precário de readaptação que não fica sob a coordenação geral do INSS, mas sim a cargo da empresa de vínculo, com pouca interferência do Estado. Não há sequer um programa de reabilitação profissional traçado por esses orientadores profissionais para cada caso. Com frequência, seus procedimentos restringem-se a entrevistar o reabilitando e a encaminhá-lo à perícia do órgão, solicitando à empresa de vínculo informações sobre o cargo a lhe ser oferecido. Sem uma avaliação criteriosa da atividade laboral oferecida pela empresa, promove-se um estágio, que, cumprido de alguma forma, resulta na homologação da reabilitação do segurado, independentemente das condições reais de efetiva reinserção no ambiente de trabalho.

Em audiência pública ocorrida em Erechim, Rio Grande do Sul, com a participação do Ministério Público Federal, do Ministério Público do Trabalho, do INSS e de trabalhadores, acerca da inexistência de um serviço de reabilitação profissional, houve um entendimento por parte do INSS de que é função da empresa realocar seus trabalhadores internamente, caso necessário. ${ }^{6}$

Pode-se citar casos reais de trabalhadores, entrevistados em sindicatos e serviços de saúde, emblemáticos, das diversas facetas dessas concepções e práticas.

Um trabalhador da região metropolitana de São Paulo, após 3 anos de afastamento por LER/DORT, foi encaminhado à reabilitação profissional do INSS. O orientador profissional solicitou à empresa, em dezembro de 2008, informações sobre as características de suas funções e atividades por meio de ofício padronizado pela Diretoria de Benefícios (OI n⿳o 116 INSS/ DIRBEN, de 25/05/2005), acompanhado por um formulário (anexo VII) ${ }^{7}$ a ser preenchido pela empresa. Em março de 2009, o setor de reabilitação profissional encaminhou-o à perícia, a despeito da ausência das informações da empresa, e o segurado teve a cessação de benefício programada para o mês seguinte, recebendo uma carta a ser entregue à empresa. Essa carta de notificação à empresa determinava:

Que o retorno às atividades laborativas deveria darse em ambiente e função adequados, sem riscos de reexposição às mesmas condições de trabalho motivadoras do aparecimento da patologia declinada, evitando-se assim o agravamento do quadro clínico, pois é da responsabilidade da Empresa a tomada de medidas preventivas necessárias[...].

\footnotetext{
${ }^{4}$ PR é a sigla de pedido de reconsideração previsto pelo INSS nos casos de indeferimento de benefício ou de sua prorrogação.

${ }^{5}$ Pergunta de um segurado. Disponível em: < http://forum.jus.uol.com.br/143322/>. Acesso em: 12 de dezembro de 2009.

${ }^{6}$ Informação de 04/04/2008, publicada no Portal do Ministério Público Federal. Disponível em: <http://noticias.pgr.mpf.gov.br/noticias-do-site/ direitos-do-cidadao/mpf-rs-discute-atendimento-de-medicos-peritos-em-erechim/?searchterm=reabilitação\%20profissional >. Acesso em: 29 nov. 2010.

${ }^{7} \mathrm{O}$ anexo VII, da Ordem Interna 116 de Diretoria de Benefícios do INSS, de 25/05/2005, cuja finalidade explicitada era "subsidiar o médico e o responsável pela orientação profissional quanto à função desempenhada pelo (a) segurado (a)", continha os seguintes itens, entre outros: descrição da função (campo aberto), exigências de escolaridade para o exercício da função, necessidade de experiência profissional, tempo mínimo exigido para aprendizagem da função, exigências na função quanto ao esforço físico, ao ritmo de trabalho, aos movimentos exigidos, às posições necessárias, à utilização da visão (campos fechados).
} 
Fica evidente a delegação da reabilitação profissional à empresa, mesmo com fortes indícios de que ela não ocorreria de fato.

Outro caso evidencia o agravamento do quadro clínico de uma trabalhadora formalmente reabilitada, mas, realmente, reexposta às mesmas situações de trabalho causadoras do adoecimento. Trata-se de uma segurada com diagnóstico de LER desde 1996, quando era caixa de banco. Após o afastamento do trabalho por aproximadamente dois anos, passou por processo de reabilitação profissional e retornou ao trabalho em 1998, tendo lhe sido concedido o auxílio-acidente. ${ }^{8}$ Apesar de formalmente reabilitada e considerada pessoa com redução de capacidade laborativa parcial e permanente, durante mais de dez anos exerceu diversas atividades que exigiam movimentos repetitivos continuados, tendo sido afastada novamente do trabalho por aproximadamente um ano, em 2007, com agravamento do quadro clínico. Esse novo afastamento não gerou qualquer procedimento do serviço de reabilitação profissional do INSS no sentido de reavaliar as condições em que a segurada estava trabalhando e, assim, ela teve cessação de benefício, retornando novamente às mesmas condições inadequadas. Em tese, para o INSS, continua a ser uma segurada reabilitada e devidamente indenizada por meio da concessão de auxílio-acidente.

Outro caso demonstra declarações contraditórias no tocante a um processo de reabilitação profissional. Trata-se de uma segurada com diagnóstico de LER e transtornos psíquicos graves, atestados por seus médicos especialistas, que, segundo o serviço de reabilitação profissional do INSS, teve "desempenho insatisfatório durante o período de estágio”, motivo pelo qual não recebeu o "Certificado de Reabilitação Profissional". No entanto, o órgão segurador declarou formalmente que a "segurada cumpriu Programa de Reabilitação Profissional no período de 20/12/2007 a 14/11/2008”. A segurada teve cessação do benefício mesmo com a declaração do INSS de que o seu desempenho laboral havia sido insatisfatório.

Esses exemplos sintetizam alguns dos problemas da reabilitação profissional, os quais são: a sua descaracterização como um serviço previdenciário; a inexistência de uma avaliação multiprofissional; a delegação da responsabilidade do estágio probatório à empresa, sem qualquer análise sobre a compatibilidade do estado de saúde e a funcionalidade do reabilitando com as atividades laborais propostas; a finalização da "reabilitação profissional" mesmo com os desempenhos insatisfatórios dos reabilitandos, cessando-lhes o benefício por incapacidade. As possibilidades dos segurados serem ouvidos no tocante às exigências das atividades laborais, à qualidade do acolhimento por parte das chefias e dos colegas são nulas, sendo-lhes negada a possibilidade de serem sujeitos de sua reabilitação profissional.

Trabalhadores com restrições frequentemente passam a ser cidadãos de segunda classe nos locais de trabalho. As grandes empresas são estimuladas a manter programas de readaptação, consolidando o seu papel capitaneador na recolocação dos trabalhadores com restrições laborais e o papel do INSS de homologador do processo, conforme permite o artigo 370 da instrução normativa de 2007 (BRASIL, 2007a). As pesquisas de acompanhamento e fixação, se feitas, não são divulgadas, de forma que não se dispõe de informações sobre a real reinserção profissional dos segurados. Uma ação civil pública promovida pela Procuradoria Regional do Trabalho da $2^{\underline{a}}$ Região, juntamente com o Sindicato dos Bancários de São Paulo, Osasco e região contra uma instituição financeira com atividades em todo o território nacional entre outros itens, refere-se ao:

tratamento indigno e discriminatório dado aos empregados portadores de LER/DORT, [...] à ausência de uma política de realocação de trabalhadores portadores de restrições funcionais, impondo dificuldades para os trabalhadores que retornam de licença médica, demissões.

Refere-se também à constatação, pelo Ministério Público do Trabalho e pelo Ministério do Trabalho e Emprego, de que "não existe política de realocação de trabalhadores portadores de restrições funcionais, impondo dificuldades para os trabalhadores que retornam de licença médica". ${ }^{9}$

\section{O desafio da construção de uma políti- ca pública de reabilitação profissional e de reinserção dos trabalhadores no mercado de trabalho}

A superação dos impasses referentes à deficiência da reabilitação profissional passa necessariamente pela compreensão do mundo do trabalho contemporâneo e pela importância das práticas de prevenção de agravos em todos os níveis de intervenção. Pochmann (2004) ajuda a entender a complexidade do contexto socioeconômico ao assinalar as características marcantes do capitalismo atual.

Segundo ele, uma das características está “associada ao aprofundamento do princípio da incerteza inerente às ações dos capitalistas”, advinda da indefinição sobre quais serão os grandes grupos econômicos que

\footnotetext{
${ }^{8}$ Benefício pago mensalmente, até a data da aposentadoria, ao trabalhador que sofre um acidente e fica com sequelas que reduzem a sua capacidade de trabalho. Corresponde a 50\% do salário de benefício que deu origem ao auxílio-doença corrigido até o mês anterior ao do início do auxílio-acidente. Disponível em: http://www1.previdencia.gov.br/pg_secundarias/beneficios_07.asp> Acesso em: 28 dez. 2009.

${ }^{9}$ Ação civil pública nº 02106.2008.004.02.00-8, promovida pelo Ministério Público do Trabalho e pelo Sindicato dos Bancários de São Paulo, Osasco e região, perante a $4^{\underline{a}}$ Vara do Trabalho de São Paulo.
} 
continuarão dominantes no contexto de incorporações e aquisições, das quais se tem notícias com muita frequência. Nesse contexto em que estão em jogo interesses financeiros de grande monta, fato recente no Brasil evidenciou a distância entre a legislação e a realidade. Trata-se da incorporação de uma empresa do setor de alimentação por outra, ocorrida em 2009. Para essas operações complexas, o governo federal dispõe de órgãos cujas atribuições referem-se à garantia dos direitos constitucionais relativos à ordem econômica e financeira (BRASIL, 1988), o que implica a análise de inúmeros itens (BASILE, 2009), entre os quais, em tese, estão as obrigações trabalhistas e a proteção da vida e da saúde do trabalhador. A despeito de dados de benefícios por incapacidade terem fundamentado a Previdência Social a definir o grau de risco máximo às empresas do setor de alimentação (BRASIL, 2009b), não se tem notícias de que a saúde do trabalhador tenha sido considerada na grande operação econômica ocorrida. Em uma grande empresa do setor, a alta prevalência de casos de LER/DORT motivou um termo de ajuste de conduta por intervenção do Ministério Público do Trabalho, visando reintegrar um grande contingente de trabalhadores adoecidos e proteger a saúde dos demais (BARTILOTTI et al., 2009).

Pochmann (2004) ainda discute uma nova divisão internacional do trabalho, que impõe uma geração de postos de trabalho de baixa qualidade nos países "com menor capacidade de desenvolvimento e de difusão de novas tecnologias".

Pode-se citar como exemplo desses postos o de operador de telemarketing. Segundo estudo realizado, constatou-se que essa população é constituída, em sua maioria, de pessoas que ingressaram aos quinze anos no mercado de trabalho em atividades diversas do mercado informal, tais como auxiliares de serviço e distribuidores de panfletos, e que não conseguiram outros espaços no mundo do trabalho. São jovens, com predominância de mulheres, muitos deles excluídos por características peculiares (obesidade, homossexualismo, negros), que se veem transitoriamente nessa atividade laboral e almejam outras colocações. São submetidos a um trabalho repetitivo, sob forte controle operacional, exigido na superação de metas inalcançáveis e com outros aspectos característicos do taylorismo (VENCO, 2009). Apesar de evidentes riscos à integridade física e psíquica, mais uma vez é possível lembrar-se de um fato que mostra a pouca importância dada às condições de trabalho e à saúde do trabalhador. Em julho de 2008, com o Ministério da Justiça à frente, foi publicado um decreto (BRASIL, 2008) regulamentando a lei (BRASIL, 1990) e fixando normas para o Serviço de Atendimento ao Consumidor (SAC). Esse decreto visou à proteção dos direitos do consumidor, que exigiu mais resolutividade e rapidez no atendimento. Se as cláusulas do decreto tiveram o objetivo de melhorar a qualidade do serviço prestado ao consumidor, a mesma preocupação não se estendeu aos trabalhadores do setor. O tempo de espera máximo do consumidor foi regulamentado, mas não há garantia das condições apropriadas para que tal rapidez seja possível sem que ocorra uma intensificação ainda maior do trabalho, com aumento da pressão sobre os trabalhadores. Mesmo a norma específica referente à saúde do trabalhador de teleatendimento (BRASIL, 2007b), previamente negociada entre representantes do governo, do movimento sindical e do setor empresarial, não tem sido devidamente implementada em função da resistência das empresas e sequer foi lembrada no processo conduzido pelo Ministério da Justiça.

Assim, a saúde do trabalhador, incluindo a reabilitação profissional, ainda é um direito constitucional a ser conquistado na prática. A inclusão das questões trabalhistas e sanitárias dos trabalhadores nas equações de sustentabilidade das políticas econômicas é de importância central para que se supere a situação de sua sobreposição ao bem-estar da população cujo ônus recai sobre o próprio Estado, seja no SUS, seja na Previdência Social ou mesmo na Assistência Social, o tripé da seguridade social no país (BRASIL, 1988).

Outro desafio a ser vencido na construção de uma política pública de reabilitação profissional refere-se à integração real entre os setores da Saúde e da Previdência Social no tocante às concepções de saúde, incapacidade, reabilitação psicossocial e profissional.

A evolução da maioria dos agravos depende de vários fatores, entre os quais a presteza na assistência, a qualidade dos cuidados terapêuticos, o apoio familiar e social, a precocidade da intervenção, visando à reabilitação física e psicossocial, necessariamente de natureza interdisciplinar, as possibilidades de afastamento do trabalho pelo tempo necessário e o processo de retorno ao trabalho, que adquire características peculiares de acordo com a natureza da restrição do trabalhador e da receptividade da empresa.

Toma-se como exemplo hipotético um trabalhador de 32 anos de idade do setor metalúrgico que, em um acidente do trabalho, sofre uma fratura exposta em uma das pernas e é atendido em um serviço de urgência. Recebe os primeiros cuidados e, por falta de vagas no hospital, aguarda alguns dias para ser operado, o que torna as suas chances de plena recuperação menores. Após a intervenção cirúrgica, preconiza-se a manutenção de cuidados e procedimentos de uma equipe multiprofissional, escassa no sistema de saúde, seja público ou privado. A recuperação desse paciente depende da gravidade da lesão, do acesso adequado à assistência, de eventuais intercorrências clínicas, da qualidade da assistência, do vínculo empregatício, da existência de cobertura previdenciária que viabilize o seu sustento durante o período em que não estiver em condições de retornar ao trabalho, do respeito ao direito legal que garante a manutenção do vínculo empregatício até um ano após o retorno ao trabalho (BRASIL, 1991), de suporte familiar e psicossocial que lhe garantam apoio no processo de recuperação. Caso tenha sequelas, por menores que sejam, a sua funcionalidade pode estar comprometida, dependendo da natureza de sua atividade 
laboral na empresa. Na impossibilidade de retornar à sua atividade laboral de origem, a sua recolocação depende da variedade de postos de trabalho oferecidos pela empresa, do acolhimento apropriado, das mudanças necessárias nos vários aspectos do trabalho e, sobretudo, de uma política e um programa definidos com o objetivo de se ampliar as suas possibilidades de reinserção, de forma acordada entre reabilitando, empresa, demais trabalhadores e órgãos governamentais. Vários desses aspectos são discutidos por Loisel et al. (2005) em casos de incapacidade decorrente da lombalgia, quais sejam, as características do trabalhador adoecido, o local de trabalho, o sistema de saúde, o seguro social, o contexto social e as interações entre os envolvidos no problema.

A reabilitação profissional pressupõe tanto o esgotamento das possibilidades da intervenção terapêutica no âmbito do setor Saúde, específicas para cada caso, como também a devida cobertura previdenciária durante o período de incapacidade para a função habitual. Essa sincronia nos procedimentos depende de uma compreensão comum das áreas da Saúde e da Previdência Social sobre os conceitos de incapacidade e de reabilitação profissional.

Tradicionalmente, o profissional de saúde a quem é atribuída a responsabilidade de avaliar a incapacidade é o médico. No entanto, durante o curso de graduação, ele não é estimulado a refletir sobre o significado de uma restrição física ou psíquica na vida de seu paciente; sua formação é centrada no raciocínio clínico, na realização diagnóstica. Além disso, os critérios que normalmente utiliza para a avaliação da incapacidade são pessoais e frequentemente descontextualizados.

Na área assistencial, a incapacidade é declarada mediante a emissão de um atestado, considerado parte integrante do ato médico, segundo resolução do Conselho Federal de Medicina (BRASIL, 2003). Esta resolução determina que o médico assistente deve especificar o tempo concedido de dispensa para a atividade, necessário para a completa recuperação do paciente, estabelecer o diagnóstico, quando expressamente autorizado pelo paciente, registrar os dados de maneira legível, identificar-se como emissor mediante assinatura e carimbo ou número de registro no Conselho Regional de Medicina.

Não entra em detalhes quanto aos critérios a serem utilizados pelo profissional. Na área pericial de uma seguradora, seus critérios passam a sofrer influências das normas e regras de conduta, explícitas e implícitas, da instituição à qual se vincula, sendo que o foco de sua atividade é o deferimento ou indeferimento de um pleito do segurado.

No caso do INSS, na perícia inicial, duas são as questões principais a serem decididas: a existência ou a inexistência de incapacidade para fins de concessão de benefício e da espécie de benefício, a depender da classificação de agravo, relacionado ou não ao trabalho. Em momentos posteriores, cabe ao perito a decisão pelo encaminhamento à reabilitação profissional, pela cessação do benefício por incapacidade ou pela indicação para aposentadoria por invalidez. Ao analisar a atividade pericial, Mendes (2006) constatou que, nas situações de difícil objetivação do adoecimento e estabelecimento do nexo causal com o trabalho, na ocasião da pesquisa, os peritos optavam por negar o benefício acidentário. Um dos peritos entrevistados chegou a verbalizar que "o perito do INSS não faz nexo causal. O paciente já vem com a CAT emitida, caracterizando acidente do trabalho. Somente aceito se a CAT for emitida pelo médico da empresa" (p. 115). Outros peritos verbalizaram o mesmo procedimento. O pesquisador constatou também a influência dos interesses do órgão segurador, o viés financeiro nas decisões periciais e as limitações do poder decisório dos peritos pelo sistema informatizado utilizado, que engessa, por exemplo, "as patologias que geram o afastamento, o tempo médio de concessão do benefício para cada patologia e os critérios de concessão de auxílio-doença”.

Considerando a zona de intersecção de atuação da Saúde e da Previdência Social, é premente a definição de critérios de avaliação da incapacidade e da funcionalidade que possam ser adotados por ambos os setores, facilitando a avaliação, a comunicação e o trabalho articulado na busca da reinserção social e profissional dos pacientes.

A base desses critérios poderia ser a mesma prevista para os fins de concessão de benefício de prestação continuada à pessoa com deficiência que não tenha como se manter, ou seja, a Classificação Internacional de Funcionalidade, Incapacidade e Saúde - CIF (BRASIL, 2007c). A Organização Mundial da Saúde considera as informações fornecidas pela Classificação Internacional de Doença (CID-10) e pela CIF, complementares, propiciando uma avaliação mais abrangente e mais precisa sobre as possibilidades de uma vida satisfatória, que depende não só das condições de saúde e doença do indivíduo, mas também do contexto do meio ambiente físico e social, das relações interpessoais, da disponibilidade de serviços e da legislação (FARIAS; BUCHALLA, 2005).

Nesse contexto, é oportuna a discussão sobre a interdisciplinaridade na definição da incapacidade, particularmente nos casos de alta complexidade clínica e social, o que permitiria tomadas de decisão baseadas em avaliações pluridimensionais.

Vencida a etapa das definições conceituais de incapacidade e reabilitação profissional, à luz das experiências (TAKAHASHI, 2006), é preciso que se definam programas de acordo com a natureza das restrições apresentadas pelo reabilitando.

O processo de reinserção profissional de um trabalhador acometido por restrições de cunho epidêmico, como ocorre nos casos de LER/DORT, é complexo e exige a mudança das condições de trabalho. Programas baseados na criação de setores destinados a trabalhadores com LER/DORT não têm apresentado sucesso no processo de reabilitação profissional, estigmatizando-os mais ainda e dando espaço para humilhações e discriminações (MAENO, 2001). Também 
é importante ter-se em conta que o retorno ao trabalho não pressupõe o controle total da dor, e sim o alcance de um estado em que se conquista certa estabilidade no quadro clínico, com diminuição da intensidade e da frequência das crises álgicas. É preciso um espaço real para a manutenção de tratamento, seja físico ou psicológico, que exija saídas durante a jornada de trabalho. Para que isso seja possível, é fundamental que haja uma relação de confiança entre o reabilitando, a equipe de reabilitação profissional e a empresa, além de uma relação trabalhista que inclua a estabilidade por tempo prolongado. Fácil compreender que, se as possibilidades de demissão forem grandes, a busca da aposentadoria por invalidez passa a ser uma alternativa, mesmo que inicialmente não desejada pelo trabalhador. Mais do que nunca, é preciso que todas as partes assumam que a reabilitação profissional é um direito legal e não uma concessão caridosa por parte da empresa ou do INSS.

Desafiadora é a reabilitação profissional de trabalhadores com transtornos psíquicos relacionados ao trabalho, cujas origens e fatores agravantes são heterogêneos, exigindo abordagens específicas no processo terapêutico e de reabilitação. Pode-se imaginar os aspectos envolvidos na reabilitação profissional de um bombeiro com estresse pós-traumático, cotidianamente exposto a situações de perigo, acidentes e catástrofes. Ou de um professor com quadro de esgotamento profissional, cuja atividade principal exige dedicação e envolvimento, considerando-se que algumas das características dessa forma de adoecimento são a despersonalização e a diminuição do envolvimento pessoal no trabalho. Ou de um bancário com quadro ansioso-depressivo grave, exigido a superar metas continuamente, sempre sob o risco de demissão. Esses exemplos refletem a necessidade de se construir abordagens específicas por natureza de restrição.

Diante dos múltiplos aspectos a serem considerados, faz-se necessário analisar com cautela a afirmação de que a nova tendência é "não reabilitar pessoas com a finalidade de fazê-las retornar ao trabalho, mas fazêlas voltar ao trabalho para reabilitá-las" (SCHUBERT, 2009). Essa ideia, sedutora à primeira vista, deve levar em conta sempre o contexto do trabalho, as suas características, a cultura organizacional e os direitos sociais para que não se promova um retorno precoce à atividade laboral, sem qualquer garantia de reinserção plena e cidadã.

Dessa forma, é urgente que os órgãos da Saúde, do Trabalho e da Previdência Social se articulem para o desenvolvimento de programas locais e regionais, colados às necessidades dos trabalhadores de sua jurisdição, em articulação com órgãos e instituições da sociedade. E, nesse processo, é mandatório considerar-se as estruturas de cada um dos setores.

Para o SUS, a vigilância em saúde do trabalhador compreende uma atuação contínua e sistemática, ao longo do tempo, no sentido de detectar, conhecer, pesquisar e analisar os fatores determinantes e condicionantes dos problemas de saúde relacionados aos processos de trabalho, em seus aspectos tecnológico, social e epidemiológico, com a finalidade de planejar e avaliar as intervenções sobre os mesmos, de forma a eliminálos (BRASIL, 1995; BRASIL, 1998).

A vigilância em saúde do trabalhador é uma das áreas que tem como característica o potencial articulador e integrador das ações de vigilância sanitária, vigilância epidemiológica e de serviços de atenção da saúde, juntamente com outros setores e instituições como a área de trabalho, a previdência e o meio ambiente (MACHADO, 1996; MACHADO, 2005). O SUS conta com uma estrutura de rede de serviços cujo funcionamento pressupõe a pactuação das diretrizes entre gestores das esferas federal, estadual e municipal de governo, cada uma delas com autonomia entre si, e a descentralização das ações, sendo, em tese, cotidiano o desenvolvimento de programas locais ou regionais, com o envolvimento do conjunto dos equipamentos da rede, cujas equipes têm composição multiprofissional. Opõe-se, assim, ao modelo anteriormente vigente de concentração da prestação de serviços por grandes estruturas, tais como ambulatórios de especialidades e hospitais, e pressupõe as unidades de saúde da rede resolutivas no seu nível de complexidade. Opõe-se ao conceito das ações de saúde centradas na figura do médico e em tese valorizam as equipes de saúde multidisciplinares em todos os níveis do atendimento. Importante passo no fortalecimento desses pressupostos foi a criação da Rede de Atenção Integral à Saúde do Trabalhador (RENAST) ${ }^{10}$, constituída por centros de referência, de composição multidisciplinar, que, na condição de equipamentos de suporte técnico, têm como objetivos atuar na disseminação das ações de saúde do trabalhador pela rede assistencial e de vigilância, com desenvolvimento de planos locais e regionais, normas e procedimentos, indicadores, programas de capacitação e articulação intersetorial (BRASIL, 2009c; BRASIL, 2006c).

No entanto, se a universalidade é uma questão resolvida, a atenção no âmbito do SUS não oferece ainda a integralidade. A precariedade da rede assistencial no acolhimento dos pacientes com transtornos de tecidos moles e dor crônica de origem musculoesquelética levou diversos desses centros de referência a desenvolverem experiências assistenciais e de reabilitação de pacientes com LER/DORT. Foram desenvolvidos modelos de programas de tratamento e reabilitação física e psicossocial, de dinâmica interdisciplinar, que, apesar de

\footnotetext{
${ }^{10}$ Segundo informações do Ministério da Saúde, em março de 2009, havia 178 centros de referências em saúde do trabalhador no país, sendo 26 estaduais e 152 regionais. Informação disponível em: < http://www.renastonline.org/renastonline/attachments/159_portaria_renast 2728. pdf > Acesso em: 13 de janeiro de 2010.
} 
evidenciarem resultados positivos, sobretudo auxiliando os pacientes no controle da dor, na recuperação da funcionalidade, na compreensão do processo de adoecimento, na recuperação da autoestima, não conseguiram efetivamente copromover, junto com o INSS, a reinserção de trabalhadores na atividade laboral pela crônica dificuldade de articulação interinstitucional e também pelo desmonte da reabilitação profissional do órgão segurador (SATO et al., 1993; SETTIMI; SILVESTRE, 1995; GARBIN; NEVES; BATISTA, 1998; SETTIMI et al., 1998; YENG et al., 2001; BRASIL, 2001e; YENG; TEIXEIRA, 2004; GUTERRES; BARFKNECHT, 2005; JACQUES, 2005; BRASIL, 2006d).

Apesar de avanços, vários são os problemas na consolidação da área de Saúde do Trabalhador no SUS, muitos deles relacionados às próprias dificuldades gerais do sistema. Pode-se citar como principais: o financiamento insuficiente, as barreiras na articulação da ação assistencial de referência e contra referência no conjunto da rede, a pouca experiência e a dificuldade de consolidar as ações de vigilância dos processos de trabalho orientadas por prioridades, a incipiente organização de rede de sistema de informação e a notificação dos eventos de saúde do trabalhador. No tocante aos recursos humanos, é crucial a falta de uma estrutura adequada de salários e de carreira que consiga fixar os profissionais em tempo integral, levando a uma elevada rotatividade no pessoal técnico, o que compromete em parte os esforços de capacitação. Embora as soluções não sejam simples, caminhos vêm sendo construídos nos âmbitos cultural, organizacional e legal (BRASIL, 2009c; BRASIL, 2006e).

No campo das ações de vigilância e da prevenção há dificuldades adicionais decorrentes do desinteresse e da obstaculização por parte dos gestores e de alguns auditores do Ministério do Trabalho e Emprego, o que contraria as diretrizes da Política Nacional de Saúde do Trabalhador (BRASIL, 2005), que indica a necessidade de ações intersetoriais entre trabalho, saúde e previdência.

Assim, essas diretrizes promissoras continuam no nível dos discursos e das intenções, visto que as iniciativas integradoras são raras e isoladas, surgindo como iniciativas pontuais nos níveis locais. Prevalecem ainda interesses corporativos, de disputa de poder, acima de uma política maior de interesse público.

Se o entendimento e a integração entre as três áreas afins (trabalho, saúde, previdência) encontram dificuldades para se consolidarem, a desejada ação intersetorial mais ampla, envolvendo setores como a economia, as políticas industriais, o meio ambiente e a educação permanece muito distante da realidade.

Na ausência desta ação transversal do Estado Brasileiro, as pastas responsáveis pelo atendimento dos pacientes com agravos gerados pelas decisões da política econômica e industrial "enxugam gelo”, pois é impossível estancar a geração de acidentados e doentes do trabalho sem modificar os processos decisórios dos quais decorre a produção dos riscos.

\section{Considerações finais}

Se, no campo da Saúde, os defensores do SUS buscam o aprimoramento dos serviços oferecidos, a consolidação da universalidade, a real integralidade, o financiamento adequado do sistema e a ampliação da participação da comunidade nas decisões sobre suas políticas e ações, na Previdência Social, predomina ainda a orientação da lógica contábil e da redução de despesas com benefícios, na qual a busca da excelência tem passado pela chamada modernização da gestão, com sistema informatizado avançado, e pela diminuição das filas dos segurados em busca de benefícios, sem que, no entanto, prevaleça a garantia dos direitos sociais constitucionais. Trabalhadores com longo tempo de afastamento do trabalho têm tido cessações de benefícios, mesmo na vigência de incapacidade parcial, sem que seja promovido um processo de reabilitação profissional adequado. Inúmeras são as situações nas quais os trabalhadores com incapacidade parcial têm seus benefícios cessados, sem ter tido acesso ao processo de reabilitação profissional, e, ao mesmo tempo, não são aprovados nos exames de retorno ao trabalho, promovidos pela empresa.

Trata-se da expressão da "letra da lei", no caso, do decreto regulamentador da Lei Previdenciária (BRASIL, 1999), que no parágrafo $1^{\circ}$ do Artigo 140, estabelece que:

Não constitui obrigação da previdência social a manutenção do segurado no mesmo emprego ou a sua colocação em outro para o qual foi reabilitado, cessando o processo de reabilitação profissional com a emissão do certificado a que se refere o caput.

A superação da situação de exclusão de trabalhadores com restrições físicas e psíquicas, decorrentes de agravos ocupacionais do mercado de trabalho, só terá possibilidade de ocorrer com a construção de uma política pública de reabilitação profissional, que deverá ter à frente o Estado, promovendo o diálogo entre as áreas de desenvolvimento econômico e as áreas sociais, concomitantemente ao desenvolvimento de uma integração de fato entre assistência, fiscalização e vigilância das condições de trabalho e previdência social. Essa integração requer o compartilhamento e a análise das bases de dados de cada área, a definição de prioridades, com programas e procedimentos articulados.

A reabilitação profissional, como meio de reinclusão social de trabalhadores com restrições, faz parte das conquistas futuras na trajetória da construção de um estado de bem-estar social, o que exige diretrizes claras por parte do Estado, como condutor deste processo, com definições conceituais, legais e intersetoriais, e com o desenvolvimento de projetos locais e regionais. Sobretudo, é preciso que a Previdência Social incorpore no seu conceito de excelência o seu caráter, de fato, público e o seu importante papel na implementação da seguridade social, com transparência institucional, que permita a ampla participação da sociedade nas decisões referentes aos seus rumos. 


\section{Referências}

BARTILOTTI, C. B. et al. Programa de Reabilitação Ampliada (PRA): uma abordagem multidimensional do processo de reabilitação profissional. Acta Fisiátrica, São Paulo, v. 16, n. 2, p. 66-75; jun. 2009.

BASILE, J. Fusão de Sadia e Perdigão desafia o Cade. Valor Online, São Paulo, 15 maio 2009. Disponível em: <http://www.valoronline.com.br/ValorOnline/ MateriaCompleta.aspx?codmateria $=5568792 \&$ dtmater ia $=2009-5-15 \&$ codcategoria $=11 \& \mathrm{tp}=3 \& \mathrm{scrollX}=0 \& \mathrm{scr}$ ollY $=0 \&$ tamFonte $=>$. Acesso em: 18 maio 2009 .

BERNARDO, L. D. Os significados do trabalho e da reabilitação profissional para o trabalhador incapacitado para o exercício da profissão habitual. 2006. 65 f. Dissertação (Mestrado em Saúde Pública)Faculdade de Medicina, Universidade Federal de Minas Gerais. Belo Horizonte, 2006.

BRASIL. Conselho Federal de Medicina. Resolução CFM nำ 1666/2003. Dispõe sobre a nova redação do anexo II da resolução CFM n⿳ำ 1.634/2002, que celebra o convênio de reconhecimento de especialidades médicas firmado entre o Conselho Federal de Medicina - CFM, a Associação Médica Brasileira - AMB e a Comissão Nacional de Residência Médica - CNRM. Disponível em: <http://www.cremesp.org. br/library/modulos/legislacao/versao_impressao. php?id=3125> . Acesso em: 25 jun. 2009 .

. Constituição da República Federativa do Brasil de 1988. Disponível em: < http://www.planalto.gov. br/ccivil_03/constituicao/constitui\%C3\%A7ao.htm>. Acesso em: 19 maio 2009.

. Decreto no 79.037 , de 24 de dezembro de 1976b. Aprova o regulamento do seguro de acidentes do trabalho. Diário Oficial [da] União, Brasília, DF, 28 dez. 1976. Disponível em: <http://www3.dataprev.gov. br/sislex/paginas/23/1976/79037.htm > . Acesso em: 04 março 2010.

. Decreto no 3.048, de 6 de maio de 1999. Aprova o regulamento da Previdência Social e dá outras providências. Diário Oficial [da] União, Brasília, DF, 7 maio 1999. Republicado em 12 de maio de 1999. Disponível em: <http://www81.dataprev. gov.br/sislex/paginas/23/1999/3048.htm >. Acesso em: 12 de abril de 2010.

. Decreto no 6.214 , de 26 de setembro de 2007c. Regulamenta o benefício de prestação continuada da assistência social devido à pessoa com deficiência e ao idoso de que trata a lei no 9.742 , de 7 de dezembro de 1993, e a lei no 10.741 , de $1^{\circ}$ de outubro de 2003, acresce parágrafo ao art. 162 do Decreto no 3.048, de 6 de maio de 1999, e dá outras providências. Disponível em: < http://www.planalto. gov.br/CCIVIL/_Ato2007-2010/2007/Decreto/D6214. htm>. Acesso em: 25 jun. 2009.

. Decreto no 6.523, de 31 de julho de 2008. Regulamenta a Lei no 8.078 , de 11 de setembro de
1990, para fixar normas gerais sobre o Serviço de Atendimento ao Consumidor - SAC. Disponível em: <http://www.planalto.gov.br/ccivil_03/_Ato20072010/2008/Decreto/D6523.htm>. Acesso em: 25 jun. 2009.

Decreto no 5.844 , de 13 de julho de 2006b. Acresce parágrafos ao art. 78 do regulamento da Previdência Social, aprovado pelo decreto no 3.048 , de 6 de maio de 1999. Diário Oficial [da] União, Brasília, DF, 14 jul. 2006. Disponível em: <http://www3. dataprev.gov.br/SISLEX/paginas/23/2006/5844.htm>. Acesso em: 04 mar. 2010.

. Decreto-Lei no 7.036, de 10 de novembro de 1944. Reforma a lei de acidentes do trabalho. Disponível em: <http://www81.dataprev.gov.br/sislex/ paginas/24/1944/7036.htm>. Acesso em: 09 nov. 2009.

. Decreto no 6.957, de 9 de setembro de 2009b. Altera o regulamento da Previdência Social, aprovado pelo decreto no 3.048 , de 6 de maio de 1999, no tocante à aplicação, acompanhamento e avaliação do Fator Acidentário de Prevenção - FAP. Diário Oficial da União, Brasília, 10 set. 2009. Disponível em: <http:// www.ntu.org.br/novosite/arquivos/Decreto6957.pdf $>$ Acesso em: 18 dez. 2009.

. Justiça Federal. Turma Recursal. Recurso contra decisão no 2008.33.00.711444-1. Recorrente: Instituto Nacional do Seguro Social - INSS.

Recorrido: Edna Maria de Jesus. Salvador, 22 jul. 2009a. Disponível em: <http://www.ba.trf1.gov.br/ TurmaRecursal/Sessoes/Sessao_109/Ss109PS/2008.33. 00.711444-1.pdf>. Acesso em: 08 nov. 2009.

. Lei no 5.316, de 14 de setembro de 1967. Integra o seguro de acidentes do trabalho na Previdência Social, e dá outras providências. Diário Oficial [da] União, Brasília, DF, 18 set. 1967. Disponível em: <http://www81.dataprev.gov.br/sislex/ paginas/42/1967/5316.htm>. Acesso em: 25 jul. 2009.

. Lei no 6.367, de 19 de outubro de 1976a. Dispõe sobre o seguro de acidentes do trabalho a cargo do INPS, e dá outras providências. Diário Oficial da União, Brasília, 21 out. 1976. Disponível em: <http:// www81.dataprev.gov.br/sislex/paginas/42/1976/6367. htm >. Acesso em: 04 mar. 2010.

. Lei no 8.078, de 11 de setembro de 1990. Dispõe sobre a proteção ao consumidor e dá outras providências. Disponível em: <http://www.planalto. gov.br/ccivil/leis/l8078.htm>. Acesso em: 09 nov. 2009.

. Lei no 8.213, de 24 de julho de 1991. Dispõe sobre os planos de benefícios da Previdência Social e dá outras providências. Disponível em: <http://www. planalto.gov.br/CCIVIL/Leis/L8213cons.htm>. Acesso em: 25 jun. 2009.

. MPS. Portaria MPS no 359, de 31 de agosto de 2006a. Diário Oficial [da] União, Brasília, DF, 01 
set. 2006. <http://www010.dataprev.gov.br/sislex/ paginas/66/MPS/2006/359.htm>. Acesso em: 03 mar. 2010.

. MPS; INSS. Instrução normativa INSS/PRES nº 20, de 11 de outubro de 2007a. Disponível em: <http://www3.dataprev.gov.br/SISLEX/paginas/38/ INSS-PRES/2007/20/CAP5.htm > . Acesso em: 10 out. 2009.

. MPS; INSS; DATAPREV. Anuário estatístico da Previdência Social: suplemento histórico (1980 a 1996). Brasília: MPS; DATAPREV, 1997. Disponível em: <http://www.mps.gov.br/arquivos/office/3 081014-111322-827.pdf $>$. Acesso em: 15 out. 2009.

. Ministério da Saúde. Portaria nº 399, de 22 de fevereiro de 2006c. Divulga o pacto pela saúde, 2006 - consolidação do SUS e aprova as diretrizes operacionais do referido pacto. Brasília, 2006. Disponível em: <http://bvsms.saude.gov.br/bvs/ saudelegis/gm/2006/prt0399_22_02_2006.html> Acesso em: 28 jan. 2010.

. Ministério da Saúde. Secretaria de Atenção a Saúde. Departamento de Ações Pragmáticas. Área Técnica de Saúde do Trabalhador. Lesões por Esforços Repetitivos (LER). Distúrbios Osteomusculares Relacionados ao Trabalho (DORT). Dor relacionada ao trabalho. Protocolos de atenção integral à saúde do trabalhador de complexidade diferenciada. Brasília: Ministério da Saúde, 2006d. Disponível em: <http:// bvsms.saude.gov.br/bvs/publicacoes/protocolo_ler_ dort.pdf > . Acesso em: 30 jan. 2010.

. Ministério da Saúde. Portaria no 3.120, de 1 de julho de 1998. Instrução normativa de vigilância em saúde do trabalhador no SUS. Disponível em: < http:// dtr2004.saude.gov.br/susdeaz/legislacao/arquivo/ Portaria_3120_de_01_07_1998.pdf > . Acesso em: 19 jan. $200 \overline{9}$.

- Ministério da Saúde. Coordenação de Saúde do Trabalhador. Divisão de Saúde do Trabalhador. Manual de normas e procedimentos técnicos para a vigilância em saúde do trabalhador no Sistema Único de Saúde - SUS. Brasília: SAS; SNVS; MS, 1995.

. Ministério da Saúde. Rede Nacional de Atenção Integral à Saúde do Trabalhador-Renast. Manual de gestão e gerenciamento. São Paulo: Renast, 2006e. Disponível em: <http://portal.saude.gov.br/ portal/arquivos/pdf/ManualRenast07.pdf $>$. Acesso em: 04 mar. 2010.

. Ministério da Saúde. Departamento de Ações Programáticas Estratégicas. Área Técnica de Saúde do Trabalhador. Diagnóstico, tratamento, reabilitação, prevenção e fisiopatologia das LER/DORT. Brasília: Ministério de Saúde, 2001e. Série A. Normas e Manuais Técnicos no 105.

. Ministério da Saúde. Portaria nº 2.728, de 11 de novembro de 2009c. Dispõe sobre a Rede Nacional de Atenção Integral à Saúde do Trabalhador (RENAST) e dá outras providências. Disponível em: < http:// www.renastonline.org/renastonline/attachments/159 portaria_renast_2728.pdf>. Acesso em: 15 dez. 2009.

. Ministério do Trabalho e Emprego. Secretária de Inspeção do Trabalho. Portaria SIT no 9, de 30 de março de 2007b. Aprova o Anexo II da NR-17. Trabalho em teleatendimento/telemarketing. Diário Oficial da União, Brasília, 02 abr. 2007. Disponível em: <http://www.mte.gov.br/legislacao/portarias/2007/ p_20070330_09.pdf >. Acesso em: 25 jun. 2009.

Portaria Interministerial no $\mathbf{8 0 0}$, de 3 de maio de 2005. Minuta de Política Nacional de Segurança e Saúde do Trabalho, elaborada pelo Grupo de Trabalho instituída pela Portaria Interministerial no 153, de 13 de fevereiro de 2004, prorrogada pela Portaria Interministerial no 1009, de 17 de setembro de 2004, para consulta pública. Disponível em: <http:// www81.dataprev.gov.br/sislex/paginas/65/mps-mtems/2005/800.htm>. Acesso em: 04 mar. 2010.

CAETANO M. A. R. Reformas administrativas para minorar o peso fiscal da Previdência Social. Texto para discussão no 1219. Brasília: IPEA. 2006. Disponível em: <http://www.ipea.gov.br/sites/000/2/publicacoes/ tds/td_1219.pdf>. Acesso em: 30 out. 2009.

CANALONGA, L. S. Projeto de revitalização da reabilitação profissional. Pró-reabilitação, 2009a. Disponível em: <http://www.proreabilitacao.com. $\mathrm{br} / \mathrm{p}=$ pc_leila_art02>. Acesso em: 09 nov. 2009.

. Reabilitação profissional. Pró-reabilitação, 2009b. Disponível em: <http://www.proreabilitacao. com.br/?p=pc_leila_art01>. Acesso em: 22 dez. 2009.

COELHO, V. S. P. (Org.). A reforma da previdência social na América Latina. Rio de Janeiro: FGV, 2003.

FARIAS, N.; BUCHALLA, C. M. A classificação internacional de funcionalidade, incapacidade e saúde da Organização Mundial da Saúde: conceitos, usos e perspectivas. Revista Brasileira de Epidemiologia, São Paulo, v. 8, n. 2, p. 187-193, jun. 2005.

GARBIN, A. C.; NEVES, I. R.; BATISTA, R. M. Etiologia do senso comum: as lesões por esforços repetitivos na visão dos portadores. Cadernos de Psicologia Social do Trabalho, São Paulo, v. 1, p. 43-55, dez. 1998.

GUTTERRES, C. M. F.; BARFKNECHT, K. S. Terapia ocupacional nas LER/DORT. Boletim da Saúde, Porto Alegre, v. 19, n. 1, p. 85-90, jan./jun. 2005.

JACQUES, M. G. Tratamentos em LER/DORT: uma abordagem interdisciplinar II: abordagem psicoterápica grupal. Boletim da Saúde, Porto Alegre, v. 19, n. 1, p. 81-84, jan./jun. 2005.

JINKINGS, N. A reestruturação do trabalho nos bancos. In: ANTUNES, R. (Org.). Riqueza e miséria do trabalho no Brasil. São Paulo: Boitempo, 2006. p. 189-205.

LOISEL, P. et al. Prevention of work disability due to musculoskeletal disorders: the challenge of implementing evidence. Journal of Occupational 
Rehabilitation, Netherlands, v. 15, n. 4, p. 507-524, Dec. 2005.

MACHADO, J. M. H. Alternativas e processos de vigilância em saúde do trabalhador: a heterogeneidade da intervenção. 1996. 151 f. Tese (Doutorado em Saúde Pública)-Escola Nacional de Saúde Pública, Fiocruz, Rio de Janeiro, 1996.

. A propósito da vigilância em saúde do trabalhador. Ciência \& Saúde Coletiva, Rio de Janeiro, v. 10, n. 4, p. 987-992, out./dez. 2005.

MAENO, M. Reinserção de trabalhadores com Lesões por Esforços Repetitivos no mercado de trabalho. 2001. 117 f. Dissertação (Mestrado em Saúde Pública)Faculdade de Saúde Pública, Universidade de São Paulo, São Paulo, 2001.

MATSUO, M. Acidentado do trabalho. Reabilitação ou exclusão? 1997. 238 f. Dissertação (Mestrado em Sociologia)-Faculdade de Filosofia, Letras e Ciências Humanas, Universidade de São Paulo, São Paulo, 1997.

MENDES, D. P. Donos do poder? Os limites e conflitos da atividade pericial frente ao estabelecimento de nexo no atual contexto da Previdência Social Brasileira. 2006. 132 f. Dissertação (Mestrado em Engenharia de Produção)-Faculdade de Engenharia, Universidade Federal de Minas Gerais, Belo Horizonte, 2006.

MORAIS, G. V. M. G. Impacto da assistência técnica do INSS nas perícias judiciais. Revista da Associação Nacional dos Médicos Peritos da Previdência Social, Brasília, n. 10, p. 32, abr./maio 2009.

OLIVEIRA, S. M. Os trabalhadores das centrais de teleatividade no Brasil: da ilusão à exploração. In: ANTUNES, R.; BRAGA, R. (Org.). Infoproletários: degradação real do trabalho virtual. São Paulo: Boitempo, 2009. p. 113-135.

PINHEIRO, T. M. M. Vigilância em saúde do trabalhador no Sistema Único de Saúde (SUS): a vigilância do conflito ou o conflito da vigilância. 1996. 147 f. Tese (Doutorado)-Universidade Estadual de Campinas, Campinas, 1996.

POCHMANN, M. As perspectivas do trabalho na economia moderna. In: DOWBOR, L. et al. (Org.). Desafios do trabalho. Petrópolis: Vozes, 2004. p. 17-24.

SATO, L. et al. Atividades em grupo com portadores de LER e achados sobre a dimensão psicossocial. Revista Brasileira de Saúde Ocupacional, São Paulo, v. 21, n. 79, p. 42-62, jul./set. 1993.

SCHUBERT, B. Reabilitação profissional no mundo. Revista da Associação Nacional dos Médicos Peritos da
Previdência Social, Brasília, p. 29-31, fev./mar. 2009. Edição especial.

SETTIMI, M. M.; SILVESTRE, M. P. Lesões por esforços repetitivos (LER): um problema da sociedade brasileira. In: CODO, W.; ALMEIDA, M. C. C. G. (Org.). Lesões por esforços repetitivos: diagnóstico, tratamento e prevenção - uma abordagem interdisciplinar.

Petrópolis: Vozes, 1995. p. 321-355.

SETTIMI, M. M. et al. Lesões por esforços repetitivos. Distúrbios osteomusculares relacionados ao trabalho: abordagem interdisciplinar. Rede, São Paulo, p. 149153, 1998. Edição especial.

SIANO, A. K. Mudanças no perfil de concessão para transtornos mentais. Revista da Associação Nacional dos Médicos Peritos da Previdência Social, Brasília, n. 10, p. 20, abr./maio 2009.

TAKAHASHI, M. A. B. C. Incapacidade e Previdência Social: trajetória de incapacitação de trabalhadores adoecidos por LER/DORT no contexto da reforma previdenciária brasileira da década de 1990. 2006. 255 f. Tese (Doutorado)-Faculdade de Medicina, Unicamp, Campinas. 2006.

TAKAHASHI, M. A. B. C.; IGUTI, A. M. As mudanças nas práticas de reabilitação profissional da Previdência Social no Brasil: modernização ou enfraquecimento da proteção social? Cadernos de Saúde Pública, Rio de Janeiro, v. 24, n. 11, p. 2661-2670, nov. 2008.

TEIXEIRA JUNIOR, G. J. A. Análise de encaminhamentos à unidade técnica de reabilitação. Revista da Associação Nacional dos Médicos Peritos da Previdência Social, Brasília, n. 10, p. 33, abr./Maio 2009.

VENCO, S. Centrais de atendimento: a fábrica do século XIX nos serviços do século XXI. Revista Brasileira de Saúde Ocupacional, São Paulo, v. 31, n. 114, p. 7-18, 2006.

. Centrais de teleatividades: o surgimento dos colarinhos furta-cores? In: ANTUNES, R.; BRAGA, R. Info proletários: degradação real do trabalho virtual. São Paulo: Boitempo, 2009. p. 153-171.

WISNER, A. A inteligência no trabalho: textos selecionados de ergonomia. São Paulo: Unesp, 1994.

YENG, L. T.; TEIXEIRA, M. J. Tratamento multidisciplinar dos doentes com dor crônica. Prática Hospitalar, São Paulo, n. 35, set./out. 2004.

YENG, L. T. et al. Distúrbios ósteo-musculares relacionados ao trabalho. Revista de Medicina, São Paulo, v. 80, p. 422-442, 2001. Edição especial. Parte 2. 